\title{
Matched T cell repertoire analysis of peripheral blood and tumor-infiltrating lymphocytes (TILs) in early stage breast cancer (ESBC) patients (pts) treated with pre-operative cryoablation (cryo) and/or Ipilimumab (Ipi)
}

\author{
David B Page ${ }^{*}$, Heather McArthur', Zhiwan Dong ${ }^{2}$, Phillip Wong ${ }^{1}$, Ryan Emerson ${ }^{3}$, Zhenyu Mu², Chunjun Zhao², \\ Christopher Comstock', Elizabeth Morris ${ }^{1}$, Elizabeth Comen ${ }^{1}$, Alan Kotinn', Janice Sung ${ }^{1}$, Edi Brogi ${ }^{1}$, \\ Monica Morrow ${ }^{1}$, Stephen Solomon ${ }^{1}$, Virgilio Sacchini ${ }^{1}$, Majid Maybody ${ }^{1}$, Deirdre Neville ${ }^{1}$, Adi Diab ${ }^{4}$, \\ Padmanee Sharma ${ }^{4}$, Harlan Robins ${ }^{5}$, Sujata Patil ${ }^{1}$, Jedd D Wolchok ${ }^{1}$, Clifford Hudis ${ }^{1}$, Larry Norton', James Allison ${ }^{4}$, \\ Jianda Yuan ${ }^{6}$
}

From Society for Immunotherapy of Cancer 29th Annual Meeting

National Harbor, MD, USA. 6-9 November 2014

\section{Background}

Cryo plus anti-CTLA-4 therapy induces antigen-specific clonal $\mathrm{T}$ cell expansion, enhanced survival, and long-term anti-tumor immunity in mice [1]. We recently demonstrated that pre-operative cryo and/or anti-CTLA-4 therapy with Ipi is well tolerated and clinically feasible in women with ESBC. Furthermore, cryo with or without Ipi generates a polyclonal influx of novel $\mathrm{T}$ cell clones within the tumor bed $[2,3]$. Here, we utilize $T$ cell repertoire analysis to explore the impact of cryo and/or Ipi on clonal expansion within peripheral blood and TILs.

\section{Methods}

In a pilot study, women with ESBC were treated with cryo $7-10 \mathrm{~d}$ before mastectomy (6 pts), single-dose Ipi (10 mg/ kg) 8-15d before mastectomy (6 pts), or cryo+Ipi (6 pts). Peripheral blood mononuclear cells (PBMCs) and tumor tissue were obtained pre-mastectomy (immediately preceding cryo and/or 1-5d after Ipi), and at mastectomy. $T$ cell repertoire analysis was conducted on extracted DNA using an Illumina ${ }^{\mathbb{B}}$ DNA deep sequencing platform and ImmunoSEQ ${ }^{\mathrm{TM}}$ software. Clones comprising $\geq 0.01 \%$

'Memorial Sloan Kettering Cancer Center, New York, NY, USA Full list of author information is available at the end of the article of sample DNA were analyzed, and results are reported descriptively.

\section{Results}

Cryo with or without Ipi was associated with decreases in absolute TIL count (median change: Ipi $+6 \%$, cryo $-73 \%$, cryo+Ipi -16\%). However, cryo+Ipi was associated with the greatest expansion of TIL clones across the range of $10^{2}-10^{4}$ amplicons (table 1 ), although no difference was observed by group in PBMC clones. Across all samples, a median of 523 TIL clones increased by $\geq 10^{2}$ amplicons, and a median of 4 TIL clones increased by $\geq 10^{3}$ amplicons. The Ipi/cryo group exceeded the median in $80 \%$ $(4 / 5)$ of cases. $21 \%$ of all TIL clones were detectable in time-matched PBMC, whereas $16 \%$ of expanding $\left(\geq 10^{2}\right)$ TIL clones were detectable in time-matched PBMC.

\section{Conclusion}

Cryo plus Ipi expands more TIL clones than either strategy alone. Therapy-associated clonal expansion may be difficult to detect in PBMCs. These data highlight the potential importance of TIL repertoire analysis for the monitoring of pts treated with cryo and/or Ipi in the preoperative setting. In a follow-up randomized study, we will evaluate whether TIL clonal expansion across the $10^{2}-10^{4}$ range can be used to predict recurrence-free survival. 
Table 1 Therapy-associated T cell clonal expansion in TILs and PBMCs.

\begin{tabular}{lllllll}
\hline & Median \# TIL clones expanding by & \multicolumn{3}{l}{ Median \# PBMC clones expanding by } \\
\hline & $\geq 10^{2}$ amplicons & $\geq 10^{3}$ amplicons & $\geq 10^{4}$ amplicons & $\geq 10^{2}$ amplicons & $\geq 10^{3}$ amplicons & $\geq 10^{4}$ amplicons \\
Cryo & 199 & 2 & 0 & 697 & 1 & 0 \\
Ipi & 750 & 22 & 1 & 545 & 5 & 0 \\
Cryo+lipi & 2010 & 85 & 1 & 830 & 1 & 0 \\
\hline
\end{tabular}

\section{Authors' details}

${ }^{1}$ Memorial Sloan Kettering Cancer Center, New York, NY, USA. ${ }^{2}$ Sloan Kettering Institute, New York, NY, USA. ${ }^{3}$ Adative Biotechnologies, Seattle, WA, USA. ${ }^{4}$ MD Anderson Cancer Center, Houston, TX, USA. ${ }^{5}$ Fred Hutchinson Cancer Center, Seattle, WA, USA. Immune Monitoring Facility, Sloan Kettering Institute, New York, NY, USA.

Published: 6 November 2014

\section{References}

1. Waitz R, Solomon $\mathrm{S}$, et al: Potent induction of tumor immunity by combining tumor cryoablation with anti-CTLA-4 therapy. Cancer Res 72:430-9.

2. Diab A, McArthur H, et al: A pilot study of preoperative (Pre-op), singledose Ipilimumab (Ipi) and/or cryoablation (Cryo) in women (pts) with early-stage/resectable breast cancer (ESBC). ASCO Annual Meeting Abs \#1098, Chicago, IL; 2014

3. Page $D$, Yuan J, et al: $T$ cell receptor (TCR) DNA deep sequencing to evaluate clonality of tumor-infiltrating lymphocytes (TILs) in early-stage breast cancer patients (pts) receiving preoperative cryoablation (cryo) and/or Ipilimumab (Ipi). ASCO Annual Meeting 2014, Abs \#3021 Chicago, IL.

\section{doi:10.1186/2051-1426-2-S3-P138}

Cite this article as: Page et al:: Matched T cell repertoire analysis of peripheral blood and tumor-infiltrating lymphocytes (TILs) in early stage breast cancer (ESBC) patients (pts) treated with pre-operative cryoablation (cryo) and/or Ipilimumab (Ipi). Journal for ImmunoTherapy of Cancer 2014 2(Suppl 3):P138.

Submit your next manuscript to BioMed Central and take full advantage of:

- Convenient online submission

- Thorough peer review

- No space constraints or color figure charges

- Immediate publication on acceptance

- Inclusion in PubMed, CAS, Scopus and Google Scholar

- Research which is freely available for redistribution 